Canadian Studies in Population, Vol. 28(1), 2001, pp. 35-67

\title{
Cultural Influence, Economic Security, and the Fertility Behavior of the Chinese in Canada
}

\section{Zongli Tang}

Massachusetts Institute for Social \& Economic Research (MISER)

University of Massachusetts at Amherst

Thompson Hall, Box 37515

Amherst, MA 01003-7515

\section{Abstract}

This study explores interactions of cultural influence and economic insecurity and their effects on the fertility behavior of the Chinese in Canada. The importance of group context on the actions of individuals is measured through data from the PUST of the 1971 and 1991 Canadian Censuses. Contextual analysis and random coefficient models are the major statistical tools employed to achieve the above objectives. The Chinese-Canadians are compared to the British-Canadians, who are used as the reference group. The findings suggest that Chinese reproductive norms with pronatalist endowments exert strong influence on the fertility behavior of the Chinese in Canada. This influence effectively counteracts the negative effects of economic insecurity and encourages Chinese immigrants to quickly recover their fertility deficit after the initial immigration stage. The effects of the origin culture on fertility diminish with increasing exposure to the host society. However, even among the nativeborn or Canadian-born Chinese, the influence of Chinese reproductive norms is still present though not as strong as among the foreign-born Chinese. 
Key Words: fertility, culture, discrimination, contextual analysis, Chinese in Canada

Résumé

Cette étude explore les interactions de l'influence culturelle et de l'insécurité économique et leurs effets sur le comportement procréateur des Chinois au Canada. L'importance d'un contexte de groupe sur les actions des individus est mesurée au moyen de données provenant de la BEGD (bande-échantillon à grande diffusion) des recensements canadiens de 1971 et 1991. L'analyse contextuelle et les coefficients de modèles au hasard constituent les principaux outils statistiques employés pour atteindre les objectifs susmentionnés. Les SinoCanadiens sont comparés aux habitants de la Colombie-Britannique qui servent de groupe témoin. Les conclusions indiquent que les normes de reproduction à action nataliste exercent une forte influence sur le comportement procréateur des Chinois au Canada. Cette influence contrebalance efficacement les effets négatifs de l'insécurité économique et encourage les immigrants chinois à se remettre rapidement de leur manque de fécondité après la première étape de l'immigration. Les effets de la culture d'origine sur la fécondité diminuent avec l'exposition à la nouvelle société hôte. Cependant, même parmi les SinoCanadiens nés en Chine ou nés au Canada, l'influence des normes de reproduction chinoises demeure présente quoique moins forte que chez les Chinois nés à l'étranger.

Mots clés : fécondité, culture, discrimination, analyse contextuelle, Chinois au Canada

\section{Introduction}

This study examines cultural effects on the fertility behavior of the Chinese in Canada. The interactions of cultural influence and economic insecurity will be also discussed. We use data from the Public Use Sample Tape (PUST) of the 1971 and 1991 Canada censuses. The unit of analysis is married females aged 20-49 of Chinese ethnicity. In order to eliminate the effects of interracial marriage, only respondents who married a Chinese person are considered in this study.

\section{Theoretical Perspective}

Human reproduction is greatly influenced by culture, and culture may explain why the population of a geographic region or an ethnic group continues to grow 
Cultural Influence, Economic Security, and the Fertility Behavior of the Chinese in Canada

in much the same way over time even though economic and demographic conditions change (Hammel, 1990).

Culture can be interpreted in many ways. In a broad sense, the value and moral system in a society can be considered an inner part or a core of the culture. Socioeconomic institutions and material conditions can be considered an outer part, which arises out of socioeconomic development within historical dynamics (Yin, 1988). Compared with the inner part, the outer part is more likely to change over time. Morals and values are only abstract principles. To afford guidance to people's daily life, these principles must be concretized to certain norms or community customs, linking ideological values to socioeconomic development. Normative movements reflect social and economic changes; however, they do not necessarily indicate essential cultural or value changes. When a society is advancing to a new stage in socioeconomic development, significant normative changes would be observed while the society's value system remains the same. Two societies or two ethnic groups at the same socioeconomic development stage would display different norms in accord with their distinct value systems.

The need of "having sons to continue generations and clans" has been the central family value in Chinese society for centuries. This value has remained resistant to any socioeconomic changes and external influences. Yet, "family size," a reproductive norm developed from this value, has evolved into several versions. In the past, the Chinese people had to bear a number of children to ensure that at least one son would survive to adulthood. Having a large family consequently became a reproductive norm at that time. With improvements made in material technology and human health status, a "large family" was no longer a necessity to raise one son. The idea of having a small family has been accepted as the reproductive norm. The family value, having a son to continue parents' lineage, has been less affected. Normative changes reflect socioeconomic progress in the same cultural context and normative differences explain cultural variations in the same socioeconomic environment. For this reason, reproductive norms, family size in particular, is chosen as a variable to measure cultural influence in this study.

In a multi-ethnic society, both the mainstream culture and ethnic subculture affect a minority member's fertility behavior. Some studies employed such questions as "home language" or "knowledge of official language" to distinguish the two types of influence. Language, a carrier of culture, is not directly related to any form of reproductive ideology. We cannot find any normative dimensions regarding family size, sex ratio, and marriage from "language." 
For certain ethnic groups, high fertility is believed to be associated with their religious doctrines. Religious orthodoxy has been found to positively correlate with Catholic fertility (Day, 1968; Noonah, 1965; Salloway, 1969). This finding has led researchers to view "religious orientation" as a specific normative characteristic of reproduction. This method, however, is not applicable to the study of Chinese culture. Confucianism, which has ideologically dominated Chinese reproductive behavior for centuries, cannot be considered a religion (Tang, 1995). That is why most Chinese do not identify themselves with any religion.

In answering such categorical questions as "language" and "religious orientation," dichotomous responses are frequently employed. Answers like "yes" or "no" cannot effectively measure slight cultural distinctions, especially when the measured variable is people's various attitudes towards family size. Lack of a refined measure has made the empirical analysis of cultural influence on Chinese reproductive behavior rare in the literature.

This study employs the average number of children-ever-born (CEB), which describes fertility trends in a long period, as the indicator of cultural influence and reproductive norms. Reproductive norms, like any community customs, usually play a long-term role. In measuring fertility trends, generation method (or CEB in this study) would be superior to a period measurement such as the total fertility rate (TFR).

Individuals act somewhat differently from collectives. In fertility decision making, individuals are often subject to various pressures from financial conditions, time, and other factors, and are unable to behave according to their ethnic reproductive norms. These non-normative factors would probably counteract each other in collective behavior. An ethnic group would thus act along the path of their ethnic norms. From this point of view, the average number of CEB for an ethnic group in a given period effectively reflects the normative influence of the group. ${ }^{1}$

Chinese fertility behavior in Canada is under the influence of both the mainstream culture and Chinese culture. The British-Canadian fertility pattern (i.e., CEB to British-Canadian women by age) in the 1991 census is considered to be the indicator of mainstream reproductive norms.

Choosing the indicator of Chinese reproductive norms is not easy. There were 586,665 Chinese-Canadians enumerated in the 1991 Canada census, consisting of two major groups: the native-born (or Canadian-born) and the foreign-born (or immigrants). The foreign-born can be further separated into adult immigrants (who entered Canada when they were beyond age 21) and child immigrants 
Cultural Influence, Economic Security, and the Fertility Behavior of the Chinese in Canada

(who entered Canada when they were under age 20). Normative influence on fertility behavior is shaped in different ways for the three subgroups.

First, the native-born Chinese are influenced by their community norms or customs mainly through what they constantly see and hear from their parents. Under this assumption, the parental fertility pattern, operationalized as the fertility of a cohort 20 years older than the current generation, is utilized as the indicator of community norms. This synthetic cohort could be obtained from the 1971 census data of Chinese women aged 20-49, who are treated as the parent generation of Chinese women in the same age range (i.e., 20-49) in the 1991 census.

Second, adult immigrants, who enter Canada when they were beyond age 21, would already have been socialized according to certain norms and attitudes regarding child bearing (Ryder, 1973). Therefore, normative influence on Chinese adult female immigrants would mainly come from their home country.

Most Chinese immigrants originated from three areas: mainland China, Taiwan, and Hong Kong. In the 1991 census, they constituted up to $81 \%$ of the total Chinese immigrants in Canada. Of them, Hong Kong Chinese accounted for 41.2\%, mainland Chinese 41.6\%, and Taiwanese $17.2 \%$. The cumulative cohort fertility rates or children-ever-born of the 1991 census in the three groups are considered to be the indicator of reproductive norms and attitudes of the sending societies. We approximate that the female immigrants would act as nonimmigrant Chinese women in these three areas if they did not immigrate to Canada. The cumulative age specific fertility rates or children-ever-born by age in mainland China, Hong Kong and Taiwan, are assigned to individual Chinese women who emigrated from corresponding areas.

Chinese immigrants, who did not originate from mainland China, Hong Kong and Taiwan, are considered to be from one of the three areas, which exhibits the socioeconomic development level similar to their home country. For instance, Chinese immigrants from Vietnam are included in the category of mainland China. Immigrants from Singapore are included as having been from Hong Kong.

Third, child immigrants, as assumed, enter Canada when they were under age 20. In most situations, they have not formed their reproductive attitudes before they arrive. Chinese traditional cultural influence on their reproductive behavior would be weaker as compared to adult immigrants, and stronger as compared to the native-born or Canadian-born Chinese. The normative influence on them would come partially from their home countries and partially from their parents. For this reason, two variables, parent generation fertility pattern and sending 
country fertility pattern, are employed to be the variable of normative influences on child immigrants.

As mentioned previously, the "large family" tradition has been replaced by the "small family" in Chinese society. However, we cannot assume that the pronatalist ideology in Chinese society has completely vanished. Traditional norms concerning family size still exert a certain influence on some Chinese families especially in countryside. Moreover, traditional family value of continuing clans and generations such as son preference (as well as universal marriage to some degree) has not lost its significance in Chinese family life (Freedman and Combs, 1974; Coale, 1980; Banister, 1987; Croll, 1985; Arnold and Liu, 1986; Freedman, 1986; Cooney and Li, 1994). These events would keep the fertility level in the Chinese world higher than that in the Western countries. In this sense, we assume that, as compared with the mainstream culture, Chinese ethnic culture encourages the Chinese in Canada to bear more children.

Chinese-Canadians are a visible minority group in Canada. Distinctive socioeconomic characteristics associated with race or ethnic membership are believed to cause fertility differentials between minorities and the majority (Lee and Lee, 1959). A major criticism of the characteristic hypothesis is provided by Goldscheider and Uhlenberg (1969). They argue that minority group status per se affects fertility independently of compositional differences between the majority and the minority. According to this criticism, minority status or discrimination against minorities engenders psychological insecurities that serve to decrease fertility. As insecurities are considered a psychological variable, it is difficult to operationalize. This explains why the minority-status hypothesis has not received overwhelming support in the literature.

We believe that discrimination brings minorities not only psychological but also physical consequences. The latter can be best explained as economic insecurity. Economic insecurity would underline Chinese cultural influence and reduce their fertility (Tang and Trovato, 1998).

This study employs relative economic status (RES) to measure degrees of discrimination or economic insecurity of the Chinese in Canada in relation to the British-Canadians. RES is the ratio of annual income per schooling year of minority members divided by the same value of majority members. ${ }^{2}$ If the RES ratio is more than unity, we assume that the Chinese have relatively better economic status than the British, and therefore greater economic security and presumably less discrimination. If the ratio is less than unity, the Chinese have relatively inferior economic status, which means less economic security (or stated differently economic insecurity compared to the British) and presumably 
Cultural Influence, Economic Security, and the Fertility Behavior of the Chinese in Canada

greater discrimination. This ratio can be calculated for individuals, social classes, and communities to determine individual economic security, class economic security, and community economic security respectively, ${ }^{3}$ thus presenting discrimination extent at the three levels.

Since this study focuses on effects of group context on individual fertility behavior, RES at the social class level or class economic security will be employed. We should mention that RES would not measure discrimination extent so accurately on adult immigrants as it does on the native or Canadianborn Chinese and child immigrants. Certain unfavorable factors resulted from immigration, poor English for instance, may make it difficult for an adult immigrant to find an appropriate job in accordance with his/her education. In addition, foreign assets, which could be a major component of immigrants' income, are not considered in RES. Therefore, we need to be cautious in explaining the economic security for immigrants. Fortunately, as this event mainly involves adult immigrants with investment classification from Hong Kong, who only account a small portion of the total immigrants, it would not significantly affect our results in general. We will discuss it further later.

With regard to attained socioeconomic status, education might be one area where minorities would perhaps experience the least discrimination. However, equalized education does not necessarily offer minority members the same job opportunities. It was observed that occupational chances of African Americans were consistently inferior to whites (Siegel, 1965; Blau and Duncan, 1967; Blau, 1992; Gill, 1993; Tang and Trovato, 1998). For example, in the National Longitudinal Survey of Young Men (NLS), there is a questionnaire regarding the desire to work in Managerial Sales and Clerical, and Craft Occupations. The findings, controlling for such factors as education and training background, indicate that blacks were significantly less likely than whites to end up working in these occupations.

Even if minority members are offered the same jobs as the majority members, there still exist pay differentials. Blau and Duncan (1967) noted that the occupational status of both the Japanese and the Chinese was higher than that of the whites, but the income level of whites was the highest of all ethnic groups. They believed that this must be attributed to ethnic status and discrimination. Minority members are more likely adopted into educational institutions than into the institutional income (Sly, 1970). The 1995 CPS (Current Population Survey) reports that people with four years education of college account for 24 percent of the whites and 29 per cent of the Asians in the United States. Meanwhile, the per capita income is $\$ 18304$ for the whites and only $\$ 16567$ for Asians. Income, especially wage differentials at the same education level, may be viewed as an objective indicator of degrees of injustice against the minority. 
Economic insecurity can be reduced by female labor force activity. If a minority husband has an inferior RES, his wife would probably work longer time to supplement family income and thus maintain living standards compatible with their social status, which is largely determined by the husband's education. The average living standard within a specific social class is usually modeled on the consumption level and the pattern of the majority group. A high level of wife's labor force participation would, other things being equal, reduce child bearing. In this sense, it could be proposed that the husband RES is a principle factor in forming a household's family size. We postulate that Chinese husbands' economic security or RES scores would positively affect their wives' fertility behavior. The higher the RES scores of the husbands, the more children born by their wives, and vise versa. Economic security or insecurity would definitely change Chinese normative influence on reproductive behavior. We hypothesize that Chinese normative influence will operate effectively when Chinese husbands make progress in their relative economic status, and vice versa.

\section{Descriptive Overview}

Table 1 shows cohort cumulative fertility rates or the average number of children-ever-born (CEB) for the British in Canada, the Chinese in three areas of origin, and the Chinese parental generation in Canada. It has been reported that the total fertility in the three Chinese areas dropped dramatically in the 1980s.

This table, however, displays a different picture and vindicates our previous argument that Chinese fertility pattern exhibits pronatalist tendencies.

Chinese fertility rates vary with areas of origin, demonstrating slight normative distinctions and socioeconomic varieties among the three areas. We did not find significant difference between the patterns of Taiwan and mainland China. In several age groups, the number of children-ever-born for mainland China is even lower than that for Taiwan. This could be attributed to the one-child policy carried out in China during the 1980s. However, after standardizing on Hong Kong age structure, the adjusted average fertility rate for mainland China remains the highest among the three areas.

The rate of children-ever-born in Hong Kong is evidently lower than that in the other two areas as Hong Kong is basically a city. This to some degree may also reveal the influence of western ideology. In addition, the geographic size may restrict the potential for population growth in this city. 
Cultural Influence, Economic Security, and the Fertility Behavior of the Chinese in Canada

The rate of Chinese immigrants' children-ever-born by sending areas is shown in Table 2. The row "total" is a series of adjusted rates standardized on the age structure of immigrants from Hong Kong. Chinese women who emigrated from mainland China hold the highest fertility rate not only at the total average but also at all age groups. This is somewhat different from the fertility pattern in sending countries as displayed by Table 1 , in which, as mentioned above, at several age groups the number of children-ever-born in mainland China is smaller than that in Taiwan.

Table 3 displays Chinese husbands' RES in the three subgroups by education and occupation. There are five educational levels: elementary school, junior high school, high school, university (undergraduate studies including bachelor degree), and postgraduate (master degree and beyond). Occupation is classified as four categories: skill I (manual jobs), skill II (clerical workers and semiskilled manual workers), skill III (semi-professionals, supervisors, and senior clerical workers), and skill IV (managers and professionals). The amount of wages would be affected by working experience. After standardizing Chinese husbands' RES on the length of British-Canadian working experience (age minus number of years in school), we did not find any significant difference as compared with the actual RES. The actual or unadjusted RES will be used in the latter analysis.

Native-born Chinese husbands hold inferior RES at three educational levels (high school, university, and postgraduate), but favorable RES at the two levels (elementary school and junior high school). The higher the education, the lower the Chinese husbands' RES. A similar trend appears in Chinese husbands' RES at four occupation categories. The higher the occupational class, the lower the RES. These figures may indicate that discrimination against the Chinese is more severe at middle and upper classes.

The RES of Chinese immigrant husbands at almost every category is worse than the native-born group. According to our calculation, the average annual wage reported in the 1991 census is $\$ 33126$ for the native-born Chinese husbands, $\$ 30347$ for child immigrant husbands, and only $\$ 25815$ for adult immigrant husbands. Obviously, immigration consequences are not financially beneficial to immigrants, especially to the adult immigrants. ${ }^{4}$ For instance, language is a disadvantageous factor for immigrants in job hunting. 


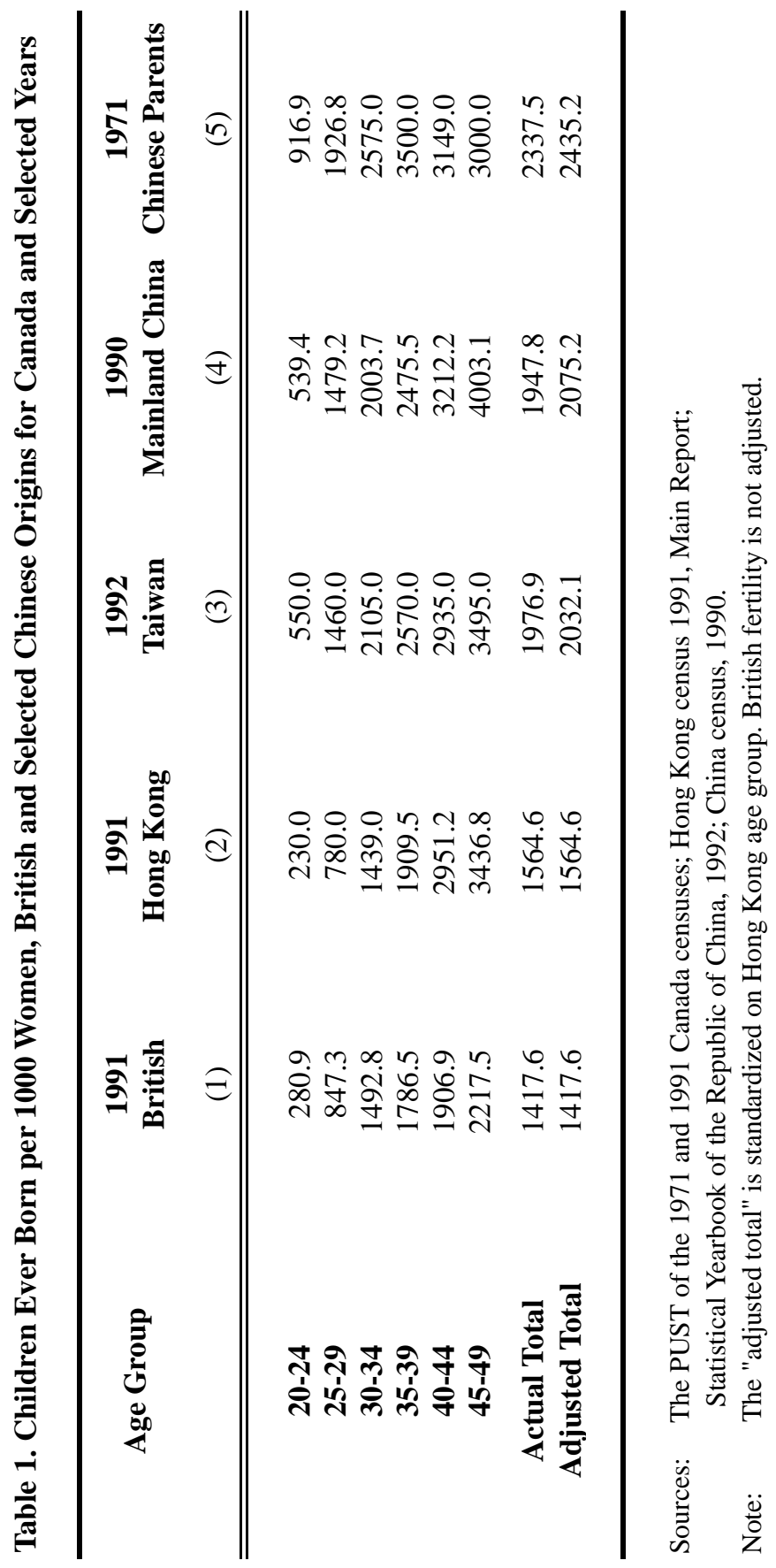


Cultural Influence, Economic Security, and the Fertility Behavior of the Chinese in Canada

Table 2

Children Ever Born per 1,000 Chinese Women Aged 20-49 Years of Selected Origins for Canada: 1991

\begin{tabular}{cccc}
\hline & \multicolumn{3}{c}{ Immigrants from Sending Countries } \\
Age Group & Hong Kong & Taiwan & Mainland China \\
& & & \\
\hline $\mathbf{2 0 - 2 4}$ & 38.3 & 88.9 & 195.1 \\
$\mathbf{2 5 - 2 9}$ & 357.4 & 400.0 & 655.8 \\
$\mathbf{3 0 - 3 4}$ & 336.1 & 1093.2 & 1258.4 \\
$\mathbf{3 5 - 3 9}$ & 1503.8 & 1648.6 & 1682.1 \\
$\mathbf{4 0 - 4 4}$ & 1742.2 & 1979.5 & 1979.7 \\
$\mathbf{4 5 - 4 9}$ & 2000.0 & 2175.8 & 1445.5 \\
& & & \\
Adjusted Total & 1021.5 & 1154.3 & 1278.0 \\
\hline
\end{tabular}

Source: PUST of the 1991 Canada census.

The RES for Chinese immigrant husbands (as classified by education) does not exactly follow the native-born pattern. Chinese husbands with junior and high school education in the child immigrant group and with high school education in the adult immigrant group possess worse RES than the well-educated. Poorly educated Chinese immigrants would be more difficult to adapt to the destination society than the well-educated. Under these circumstances, the RES for immigrants is a variable compounding discrimination, assimilation, and disruption. On the other hand, however, Chinese immigrant husbands' RES at four occupational categories displays the trend similar to the native-born group: the higher the occupational class, the lower the RES, suggesting that discrimination against Chinese immigrants is still more severe at middle and upper classes. 


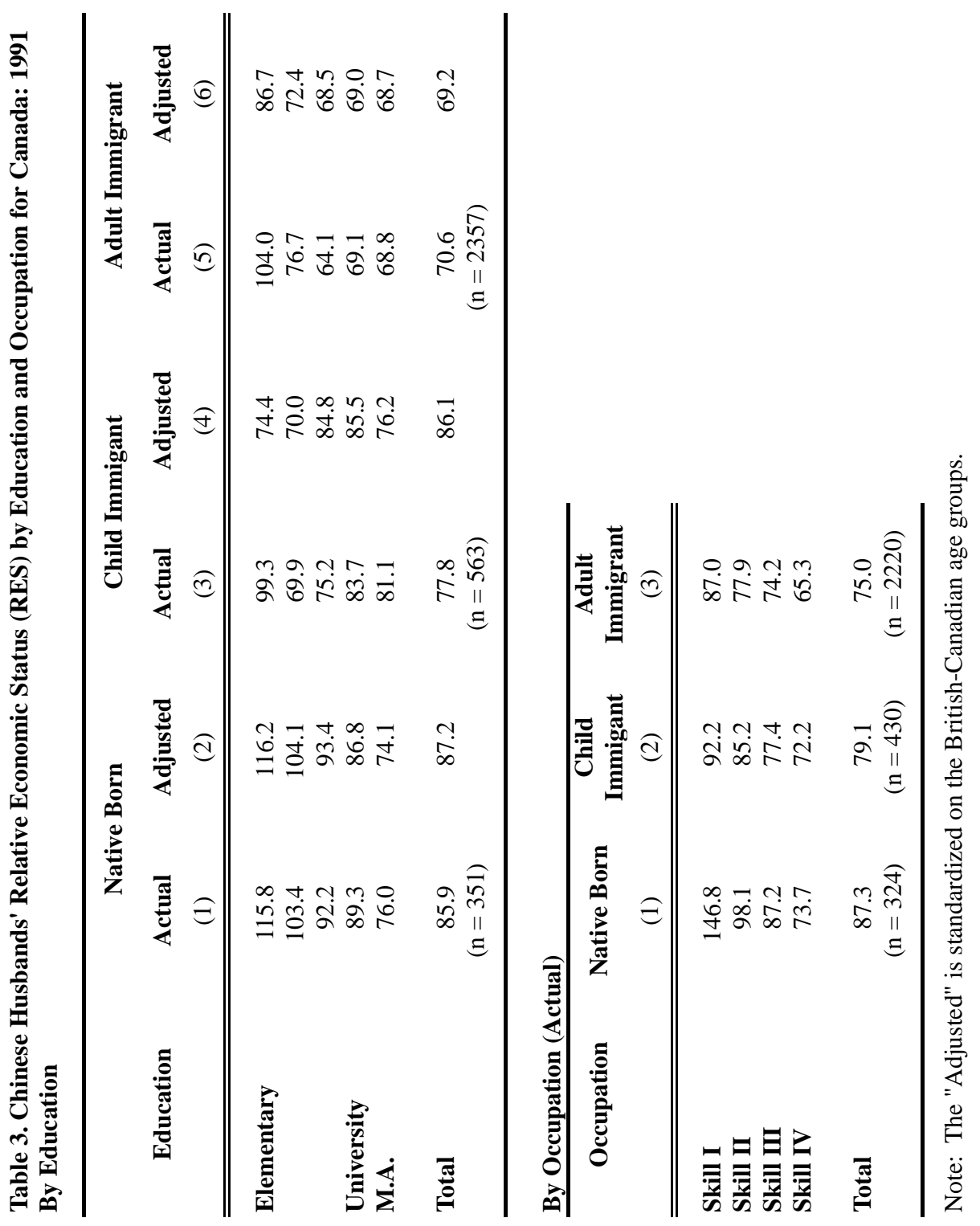


Cultural Influence, Economic Security, and the Fertility Behavior of the Chinese in Canada

RES scores for two immigrant groups are lower than for the native-born group. The RES for the adult immigrant group is the worst. Under the insecurity hypothesis, immigrants, especially adult immigrants, would have fewer children than the native-born. On the contrary, as shown by Table 4, their actual CEB number at the average is larger than the native-born group's. This would be attributed to the following reasons. First, RES may not accurately measure immigrants' economic security as explained before. Second, Chinese pronatalist cultural influence offsets negative effects of economic insecurity.

\section{OLS Model and Normative Influence}

OLS model is applied to examine normative influences on Chinese fertility behavior. The equation is given by:

$$
Y_{i}=\beta_{o}+\beta_{j} X_{i j}+\xi_{i}
$$

here $\mathrm{Y}_{\mathrm{i}}$ is the dependent variable CEB (children-ever-born by married Chinese females aged 20-49), $X_{i j}$ represents $j$ independent variables of woman $i, \beta_{0}$ the intercept, $\beta_{\mathrm{j}}$ coefficients, and $\xi_{\mathrm{i}}$ the error term. The model expressed in Equation 1 is estimated separately for each Chinese group. Chinese women who identified themselves as Christians in the PUST are not considered in this study. Chinese women aged 45-49, who entered Canada between 1986 and 1991, are not included either because they probably finished their reproduction before arriving in Canada.

\section{Native-born Chinese}

As mentioned above, Chinese fertility behaviour is affected by both the mainstream culture and their ethnic culture. The former is operationalized as the average number of children-ever-born for British women (at all marital status) in the 1991 census (BFP). The latter is represented by Chinese parental fertility pattern (PFP) and operationalized as the children-ever-born to Chinese women aged 20-49 (at all marital status) in the 1971 census. ${ }^{5}$ The two variables are all disaggregated by age into individual women. The remaining independent variables are women's age (AGE), education (EDU, total years of schooling), 
Table 5

OLS Model on Chinese Children Ever Born for Canada: 1991

\begin{tabular}{lccc}
\hline \multicolumn{1}{c}{ Variable } & B & Beta & sig T \\
\hline \hline Native-born & & & \\
BFP & 0.3410 & 0.0870 & 0.2220 \\
AGE & 0.0583 & 0.4176 & 0.0001 \\
EDU & -0.0530 & -0.1940 & 0.0022 \\
EMP & -0.0720 & -0.0190 & 0.5550 \\
FPT & -0.0660 & -0.0230 & 0.3000 \\
WAGE & -0.000003 & -0.0340 & 0.1430 \\
WEEKS & -0.0024 & -0.0350 & 0.5410 \\
PFP & 0.3740 & 0.2830 & 0.0000 \\
$\quad$ Multiple R $=\mathbf{0 . 5 6 2}$ & & \\
$\quad$ Sig F $=\mathbf{0 . 0}$ & & & \\
\hline
\end{tabular}

Child Immigrants

\begin{tabular}{lccc}
\hline \hline BFP & 0.5460 & 0.2410 & 0.1430 \\
AGE & 0.0614 & 0.4226 & 0.0000 \\
EDU & -0.0940 & -0.3200 & 0.0000 \\
EMP & -0.0740 & -0.0170 & 0.6410 \\
FPT & -0.3330 & -0.1150 & 0.0040 \\
WAGE & -0.0000069 & -0.0930 & 0.1430 \\
WEEKS & -0.00071 & -0.0100 & 0.8250 \\
PFP & 0.1230 & 0.0840 & 0.2420 \\
CFP & 0.3170 & 0.2480 & 0.0010 \\
$\quad$ Multiple R $=\mathbf{0 . 6 4 7}$ & & \\
Sig F = 0.0 & & \\
\hline
\end{tabular}

\begin{tabular}{lccc} 
Adult Immigrants & & & \\
\hline \hline BFP & 0.0001 & 0.1030 & 0.0139 \\
AGE & 0.0637 & 0.4317 & 0.0000 \\
EDU & -0.0670 & -0.1810 & 0.0000 \\
EMP & -0.1910 & -0.0350 & 0.3410 \\
FPT & -0.4840 & -0.1850 & 0.0060 \\
WAGE & -0.0000088 & -0.1350 & 0.0480 \\
WEEKS & 0.0030 & -0.0410 & 0.1380 \\
CFP & 0.7630 & 0.4690 & 0.0000 \\
\multicolumn{2}{c}{ Multiple R $=\mathbf{0 . 5 2 0} \quad \mathbf{F}=\mathbf{0 . 0}$} & & \\
\hline
\end{tabular}


Cultural Influence, Economic Security, and the

Fertility Behaviour of Chinese in Canada

labour force status (EMP dummy variable, $1=$ in labour force, $0=$ not in labour force), weeks worked in 1990 (WEEKS), annual wage (WAGE), and employment status (FPT, dummy variable, $1=$ full time job, $0=$ part time job). $Y_{i}$ is the number of children-ever-born (CEB) by individual native-born Chinese married women aged 20-49 in the 1991 census. The coefficients, Beta values and probabilities (significant $\mathrm{T}$ values) are summarised in Table 5. EDU, WAGE, and labour force activity variables including WEEKS, FPT, and EMP exert negative effects on CEB. Effects from PFP and BFP are positive. But, BFP is not statistically significant. PFP's Beta value is substantially larger than BFP's, indicating that Chinese reproductive norms play a more important role in forming native-born Chinese fertility than the mainstream culture does.

\section{Child Immigrants}

For this group, the variable of Chinese reproductive norms is operationalized as parent generational fertility pattern (PFP) and the sending country fertility pattern (CFP). British fertility pattern (BFP) is regarded again as the indicator of reproductive norms in the mainstream culture. The remaining independent variables are the same as those in the native-born model. The coefficients, Beta values, and probabilities (sig T - significance levels) are summarised in Table 5. We only need to discuss the three normative variables. All the three variables have positive effects on child immigrants' fertility. However, it is only the sending country fertility pattern (CFP) that achieves statistical significance, demonstrating that Child immigrants' fertility behaviour would be more closely related to reproductive norms in their home countries. The sum of Beta value for CFP and PFP is larger than PFP in the native-born group, which may demonstrate stronger Chinese cultural influence on child immigrants.

\section{Adult Immigrants}

Fertility patterns or the average numbers of CEB in mainland China, Taiwan and Hong Kong (CFP) are used in the analysis of cultural effects on Chinese adult immigrants. Once again, British group fertility pattern (BFP) is regarded as the indicator of mainstream culture. The coefficients, Beta values and significance levels are summarised in Table 5.

For the first time the British fertility pattern achieves statistical significance, but Beta and $\mathrm{T}$ values are not as strong as Chinese fertility pattern in the sending countries, which, in terms of Beta values, alone makes up nearly $50 \%$ of the changes in adult immigrants' fertility. Also in terms of the Beta values, we found 
that the CFP effect in the adult model is the strongest among the three models, reflecting adult immigrants' longer socialisation in their home countries.

\section{Multi-level Analysis, Normative Influence, and Economic Insecurity}

In this section, we will employ contextual analysis and multi-level models to examine the compound effects of cultural influence and economic insecurity on Chinese fertility behaviour.

The importance of group context on individual actions is the focus of this section. . As observed previously, discrimination against Chinese-Canadians varies with social classes, and the normative context changes across the three subgroups. We hypothesise that a Chinese wife's child bearing is affected not only by her individual socioeconomic and demographic characteristics, but also by the socioeconomic environment around her.

This study involves two levels: macro or community level and micro or individual level. At the community level, the Chinese people in Canada could be classified by immigrant status (i.e., the native-born, child immigrants, and adult immigrants), as well as social classes, (operationalized as five educational levels, elementary school, junior high school, high school, university, and MA degree plus). Obviously, this is a model of cross-classified level. Correspondingly, we have two variables at the level: Chinese husbands' RES, a structural variable of social classes, and Chinese fertility pattern, a normative variable of immigrant-status groups. ${ }^{6} \quad$ Chinese woman's childbearing is influenced by discrimination against her husband within any given social class, and by reproductive norms in her immigrant-status group.

Data on the socio-economic variables of the husband and the wife in a family are recorded in the PUST family file. Unfortunately, this file does not contain explicit information on the Chinese (as they are lumped with "other ethnicities"). As an alternative, data from the individual file are used on the assumption that married Chinese males are the husbands of married Chinese females in the same file. Since this study focuses on the role of group context on individual behaviour, this assumption is not very problematic. Generally, the age difference between wives and husbands is about two years (husbands being older). Married males aged 22-51 are included in this study to complement the females aged 2049. In the case of the Chinese, it is commonly held that traditionally, Chinese women should not marry men who are less educated than they (Cheung, 1988; Leete, 1994). In fact, we found from the family file in the 1980 Canada census that $67.3 \%$ of Chinese women were married to Chinese men with the same 
Cultural Influence, Economic Security, and the

Fertility Behaviour of Chinese in Canada

education and $28.2 \%$ of them were married to men with higher education. Accordingly, we assume that Chinese wives are in the same social class as their husbands.

Chinese women's socioeconomic characteristics including age, income, education, labour force activities, and immigration years are employed as structural variables at the individual or micro level. For the convenience of discussion, the British-Canadian fertility pattern, the indicator of mainstream culture, is regarded as a normative factor at the individual level.

The two-level cross-classified random coefficient model (RC) is applied to this analysis ${ }^{7}$. The equation is given as

$$
\begin{aligned}
& Y_{i(j k)}=\eta_{o o}+\eta_{o 1} Z_{1 i j}+\eta_{o 2} Z_{2 i j}+\eta_{o 3} G_{1 j}+\eta_{o 4} G_{1 k} \\
& +\eta_{p o} X_{p i(j k)}+\left(\alpha_{o(j k)}+X_{p i(j k)} \alpha_{p(J K)}+\xi_{i(j k)}\right)
\end{aligned}
$$

Here, $\mathrm{Y}$ is the micro dependent variable, representing the children-ever-born by Chinese-Canadian women aged $20-49, \mathrm{j}=1, \ldots \mathrm{J}$, and $\mathrm{k}=1, \ldots \mathrm{K}$ denote contexts at the cross-classified macro level, and $\mathrm{i}=1, \ldots \mathrm{n}_{\mathrm{jk}}$ denotes the micro observation within these contexts. The ith Chinese married woman is classified by the $j$ th social class (elementary school, junior high school, high school, university, and $\mathrm{MA}+$ ), and $k$ th group (native-born, child immigrant, and adult immigrant).

Immigrant status is measured by two dichotomous dummy variables $Z_{1 \mathrm{ij}}$ and $\mathrm{Z}_{2 \mathrm{ij}}$. Chinese married women are given a score of one if they fall within a given immigrant subgroup (adult immigrant $=1$, and child immigrant $=1$ ). The nativeborn Chinese are the reference group and are given a score of zero for both of these dummy variables. When scored in this manner, the estimates of the regression coefficients of the two dummy variables may be interpreted as the average deviation in fertility of the immigrant status group from the mean fertility of the native-born Chinese.

We have $\mathrm{p}$ explanatory variables $\mathrm{X}_{\mathrm{pi}(\mathrm{k})}(\mathrm{p}=1, . . \mathrm{P})$ at the individual level, one explanatory variable $G_{1 j}$ at the social class level, and one explanatory variable $\mathrm{G}_{1 \mathrm{k}}$ at the sending area level.

This model is a mixed model, containing fixed coefficients (the $\eta$ 's) and random coefficients (the $\alpha$ 's). A fundamental assumption of a RC model is that the elements at both group and individual levels are randomly sampled. Some 
scholars have considered social classes as fixed categories. In this study, however, social classes as well as immigrant groups are assumed to be randomly sampled for the following reasons: First, classes and groups are categorised on randomly selected individuals. Second, classes and groups in this study are a sample of classes and groups in the society.

Following the approach adopted by Hox (1994) in his research, we first examine the micro-level-only model, which contains two immigrant status dummy variables (ADULTG and CHILDG), and eight explanatory variables at the individual level, including age (AGE), wage (WAGE), labour force status (EMP: in labour force $=1$, not in labour force $=0$ ), employment status (FPT, full time $=1$, part time $=0$ ), weeks worked in 1990 (WEEKS), education (EDU, total years of schooling), immigration years (IMM), an indicator of assimilation, and British community fertility pattern (BFP). Since the native-born Chinese do not have a period of immigration, they are all assigned a total of 50 years of immigration to represent the longest duration of residence in Canada, meaning that they are more assimilated. On the assumption that the term $X_{\mathrm{pi}(\mathrm{k})} \alpha_{\mathrm{p}(\mathrm{k})}$ is zero, Equation 2 then simplifies to

$$
Y_{i(j k)}=\eta_{o o}+\eta_{o 1} Z_{1 i j}+\eta_{o 2} Z_{2 i j}+\eta_{p o} X_{p i(j k)}+\left(\alpha_{o(j k)}+\xi_{i(j k)}\right)
$$

(terms defined previously).

The MLn program is employed in the computation ${ }^{8}$.

The parameters, estimates, constant, and two variance estimates, $\sigma_{\xi}^{2}$ for the residual variance at the class level, and $\sigma^{2}$ for constant variance at the individual level, are summarised in Table 6. All variables except BFP and WEEKS are statistically significant at the $5 \%$ level.

Controlling for these variables at the micro-level, Chinese adult immigrants hold the highest fertility among the three subgroups. Socio-economic variables including EDU, WAGE, EMP, FPT, and WEEKS have negative effects on Chinese fertility behaviour. This is consistent with observations in most previous studies. The variable BFP is not statistically significant, suggesting that the mainstream culture exerts very little influence on the fertility behaviour of the Chinese in Canada.

IMM, the variable of assimilation, has a positive effect, indicating that increased length of stay in Canada encourages rather than depresses Chinese fertility. For immigrants, the variable "immigration years" could also be understood as an indicator of disruption, which would be weakened with prolonged residence in Canada. In other words, when Chinese immigrants passed through the initial 
Cultural Influence, Economic Security, and the Fertility Behaviour of Chinese in Canada

period of immigration, they would probably speed their child-bearing as directed by their ethnic culture. This finding reminds us that the role of acculturation in Chinese fertility behaviour is not so important as imagined. The influence of Chinese pronatalist culture is so strong that it did not diminish much with longer residence in Canada.

The next step involves the addition of the macro level variable $G_{1 j}$, Chinese husbands' RES at the five education levels. The equation is given as

$Y_{i(j k)}=\eta_{o o}+\eta_{01} Z_{1 i j}+\eta_{02} Z_{2 i j}+\eta_{03} G_{l j}+\eta_{p o} X_{p i(j k)}+\left(\alpha_{o(j k)}+\xi_{i(j k)}\right)$

(terms defined previously).

The parameter estimates, constant, and variances are listed in Table 6. We found that the RES brings a positive effect on Chinese fertility behaviour. This confirms our previous hypothesis that the improvement of economic security or the reduction of discrimination against the Chinese would encourage ChineseCanadians to have more children.

The third step involves the addition of another macro level variable $G_{1 k}$ or Chinese fertility pattern (CFP), and is determined by Equation 2. For child immigrants, as mentioned previously, the fertility pattern in sending areas plays a more important role than the parental fertility pattern does. Thus, the parental fertility pattern is not considered this time

The results for Equation 2 are summarised in Table 7. All variables except for BFP and WEEKS are statistically significant at the 5\% level. Chinese fertility pattern, the indicator of Chinese normative influence, as observed in the OLS model, holds a positive effect on the fertility behaviour of the Chinese in Canada. The level II or the macro level variance estimate is 0.009887 , which is less than the estimate of 0.0891 in Equation 4. The estimates of two immigrantstatus dummy variables are larger than those in Equation 4, suggesting that the addition of the normative factor to the equation significantly raises the fertility of the two immigrant groups. 
Table 6

Results of RC Models for Chinese Wives Aged 20-49

for Canada: 1991

\begin{tabular}{lll}
\hline Variables & \multicolumn{2}{c}{ Model Equations } \\
& (3) & (4) \\
\hline \hline
\end{tabular}

Fixed Part

Individual Level

Constant

ADULTG

CHILDG

AGE

EDU

IMM

BFP

WAGE

EMP

FPT

WEEKS

$\begin{array}{cc}-0.07672 & -0.006901 \\ 0.5550 & 0.4514 \\ 0.0738 & 0.5862 \\ 0.05543 & 0.05701 \\ -0.06007 & -0.06038 \\ 0.01513 & 0.01433 \\ 0.38112 * & 0.42061 * \\ -0.00006 & -0.00001 \\ -0.18272 & -0.17361 \\ -0.12323 & -0.10124 \\ -0.00011 * & -0.00121 *\end{array}$

Class Level

RES

0.00339

\section{Random Part}

$\begin{array}{lll}\sigma_{\xi}^{2} & 0.6228 & 0.7064 \\ \sigma_{v}^{2} & 0.2744 & 0.0891\end{array}$

$\begin{array}{ccc}\text { Deviance } & 8777.1 & 8687.9 \\ \chi^{2} & 3.7 \text { e-8 } & 2.6 \text { e-5 }\end{array}$

Note: Variables, except for these with *, are statistically significant at the level of 0.05 . 
Cultural Influence, Economic Security, and the Fertility Behaviour of Chinese in Canada

The model for Equation 5 is a complete cross-classified model and includes the interaction terms of micro and macro variables:

$$
\begin{gathered}
\eta_{p o} X_{p i(j k)}+\eta_{p 1} X_{p i(j k)} G_{l j}+\eta_{p 2} X_{p i(j k)} G_{l k} \\
+\eta_{p 3} X_{p i(j k)} G_{l j} G_{l k}+\left(\alpha_{o(J K)}+X_{p i(j k)} \alpha_{p(j k)}+\xi_{i(J K)}\right) \\
Y_{i(j k)}=\eta_{o o}+\eta_{o 1} Z_{l i j}+\eta_{02} Z_{2 i j}+\eta_{o 3} G_{l j}+\eta_{o 4} G_{l k}+\eta_{o 5} G_{l j} G_{l k}
\end{gathered}
$$

The following interaction terms are considered: RES with immigration years (RESIMM), RES and Chinese fertility pattern with immigration years (RCI), Chinese community fertility with immigration years (CFPIMM), adult immigrant dummy variable with RES (ADURES), adult immigrant dummy variable with Chinese fertility pattern (ADUCFP), adult immigrant dummy variable and RES with Chinese fertility pattern (ADURESCFP), child immigrant dummy variable with RES (CHIRES), child immigrant dummy variable with Chinese fertility pattern (CHICFP), and child immigrant dummy variable and RES with Chinese fertility pattern (CHIRESCFP).

Some interaction terms (those marked with a star in Table 7) do not achieve statistical significance. The level II or the macro level variance estimate (0.004695) is less than the estimate of 0.009887 in Equation 2. The interaction term "RCI", which represents a compound effect of economic securities, Chinese reproductive norms, and immigration process, exerts a positive impact on Chinese fertility behavior. "RESIMM" has a negative effect. Obviously, the addition of interaction terms raises estimates of the two immigrants-status dummy variables, especially the adult immigrant dummy variable.

After the addition of interaction terms, the estimates of two immigrant-status dummy variables do not accurately reflect the effects of immigrant status on children-ever-born as these effects depend heavily on the scores of RES and CFP. Table 8 displays the immigrant-status effects conditional on specified levels of RES and CFP. To find changes in the two immigrant status dummy variables, the average number of children-ever-born in the three sending areas (Hong Kong, Taiwan, and mainland China) rather than in the three subgroups is used to represent CFP. 
Table 7

Two-Level Cross-Classified Models

Chinese Wives Aged 20-49 for Canada: 1991

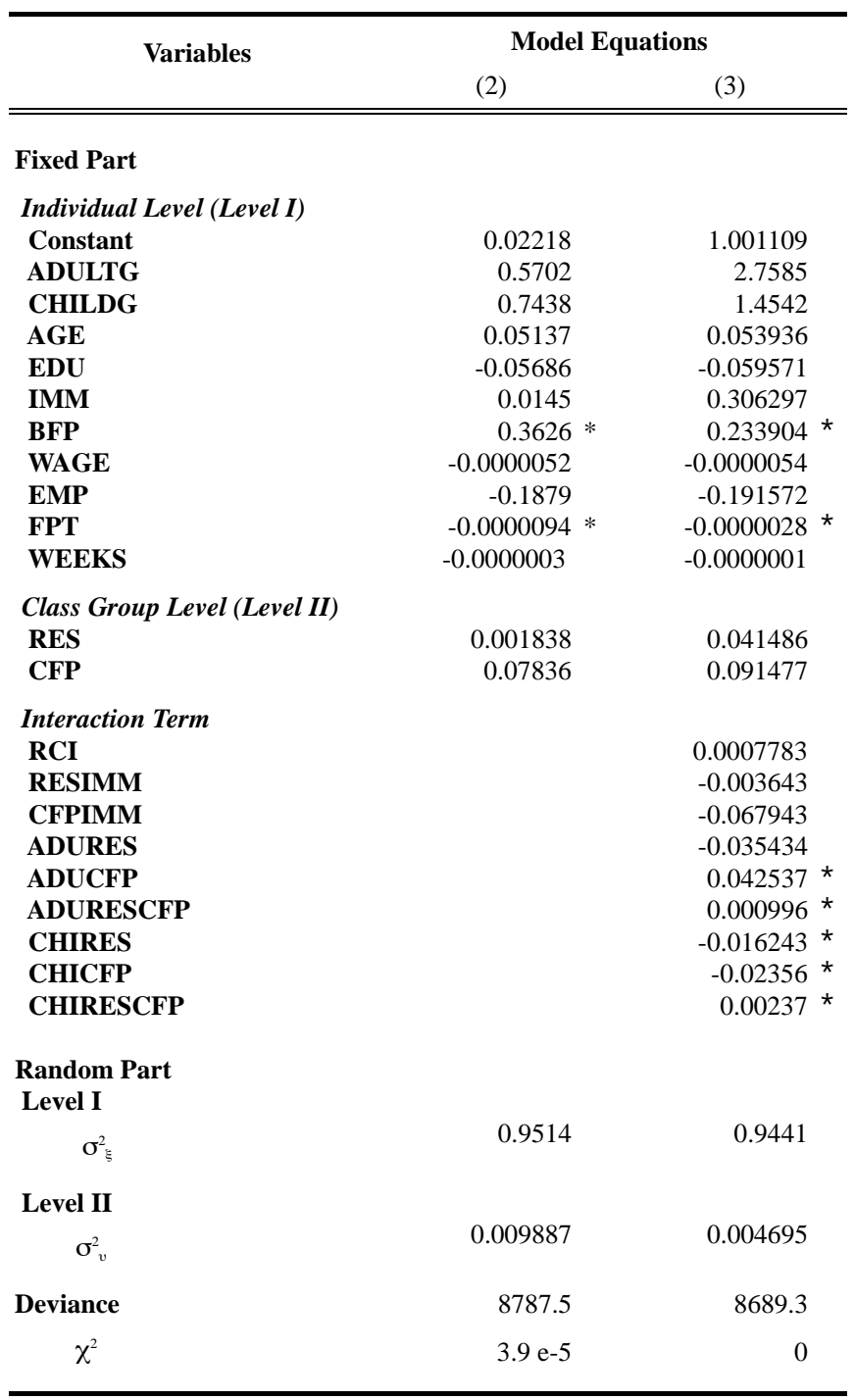

Notes: Variables, except for those with *, are statistically significant at the level of 0.05 . 
Cultural Influence, Economic Security, and the

Fertility Behaviour of Chinese in Canada

Table 8

Immigrant Contrast Conditional On Relative Economic Status (RES) and Country Fertility Pattern (CFP) for Canada: 1991

\begin{tabular}{|c|c|c|c|}
\hline \multirow[b]{2}{*}{$\begin{array}{l}\text { RES } \\
(\%)\end{array}$} & \multicolumn{3}{|c|}{ CFP } \\
\hline & $\begin{array}{l}\text { Hong Kong } \\
(\mathrm{CFP}=1.565)\end{array}$ & $\begin{array}{c}\text { Taiwan } \\
(\mathrm{CFP}=2.032)\end{array}$ & $\begin{array}{c}\text { Mainland China } \\
(\mathrm{CFP}=2.075)\end{array}$ \\
\hline \multicolumn{4}{|c|}{ Adult Immigrants } \\
\hline $\begin{array}{l}\text { Elementary } \\
(\mathrm{RES}=104)\end{array}$ & -0.703 & -0.649 & -0.629 \\
\hline $\begin{array}{l}\text { Junior High } \\
\text { (RES=76.7) }\end{array}$ & 0.223 & 0.278 & 0.283 \\
\hline $\begin{array}{l}\text { High School } \\
(\mathrm{RES}=64.1)\end{array}$ & 0.651 & 0.699 & 0.704 \\
\hline $\begin{array}{l}\text { University } \\
(\mathrm{RES}=69.1)\end{array}$ & 0.481 & 0.532 & 0.537 \\
\hline $\begin{array}{l}\text { M.A.+ } \\
(\mathrm{RES}=68.8)\end{array}$ & 0.491 & 0.542 & 0.547 \\
\hline \multicolumn{4}{|c|}{ Child Immigrants } \\
\hline $\begin{array}{l}\text { Elementary } \\
(\mathrm{RES}=99.3)\end{array}$ & 0.173 & 0.272 & 0.281 \\
\hline $\begin{array}{l}\text { Junior High } \\
(\mathrm{RES}=69.9)\end{array}$ & 0.541 & 0.608 & 0.614 \\
\hline $\begin{array}{l}\text { High School } \\
(\mathrm{RES}=75.0)\end{array}$ & 0.477 & 0.549 & 0.556 \\
\hline $\begin{array}{l}\text { University } \\
(\mathrm{RES}=83.7)\end{array}$ & 0.368 & 0.450 & 0.457 \\
\hline $\begin{array}{l}\text { M.A.+ } \\
(\mathrm{RES}=81.1)\end{array}$ & 0.400 & 0.479 & 0.487 \\
\hline
\end{tabular}


From this table, we found that the two immigrant groups' net deviations of children-ever-born from those of the native-born Chinese increase with the shifting from the sending area with low fertility pattern to the area with high fertility pattern. For instance, in the adult immigrant group, for Chinese women who come from Hong Kong and whose husbands' RES scores are 76.7 (i.e., at the junior high school education level), the average number of children ever born is 0.223 more than that for the native-born Chinese. For these women who are at the same class but who come from mainland China, this value is 0.283. This finding indicates that reproductive norms positively affect Chinese fertility behavior.

As assumed, Chinese women whose husbands feel relatively economically secure would like to bear more children. This trend is obvious to the native-born Chinese (Tang and Trovato, 1998). For this group, the higher the husbands' education level, the worse the economic security, and the lower the wives' relative fertility level (as illustrated in Column 2 in Table 4).

Yet, this trend is not clear for immigrants. Table 8 shows that the two immigrant groups' net deviations decrease with the shifting from low RES scores to high RES scores. For example, at the highest RES level $($ RES $=104)$ in the adult immigrant group, Chinese women who emigrated from Hong Kong have an implied average of 0.703 children fewer than the native-born Chinese women. At the lowest RES level (RES = 64.1), Chinese women also from Hong Kong have an implied average of 0.651 children more than the native-born Chinese. That is to say, the favorable RES discourages rather than raises Chinese immigrant child bearing. The role the RES plays in immigrant fertility behavior seems different from what it plays in the native-born group. We provide the following explanations.

First, native-born Chinese people's RES becomes worse with increasing education. This type of relationship, however, does not exist clearly in the two immigrant groups. As mentioned previously, RES scores would not accurately measure the extent of discrimination against immigrants and would not adequately reflect immigrants' economic security either. With such possibilities, the fertility comparison between the native-born and immigrant groups would probably be distorted when controlling for RES.

Second, cultural or normative influence may prevail over economic effects on the immigrants. In reference to cultural influence, Chinese immigrants, especially the well educated, do not mind bearing more children even if their RES is not as good as their native-born compatriots'. 
Cultural Influence, Economic Security, and the Fertility Behaviour of Chinese in Canada

Finally, as compared to immigrants, the native-born Chinese fertility highly depends on RES levels. When their RES scores reach more than unity, their CEB (children-ever-born) would likely resemble the maximum level required by the ethnic reproductive norms. Since the reproductive process of immigrants is often highly disrupted by immigration affairs, the poorly educated immigrants, even when they have the same relative economic security as the native-born, would not be able to bear as many children as their ethnic values dictates. This may explain the negative deviation of the adult immigrant group from the mean fertility of the native-born Chinese at the low classes. Furthermore, in the face of deteriorating RES, the native-born Chinese would quickly respond by reducing child bearing. For immigrants, however, strong traditional cultural influences slow the negative effects of RES, thus keeping the fertility at a certain level. In this context, a positive fertility gap between the two subgroups would likely appear. This positive gap would be widened with decreasing RES scores.

The table shows that poorly educated child immigrants bear more children than adult immigrants with the same education, suggesting the more powerful impact of disruption on the latter. Meanwhile, the well-educated child immigrants have fewer children than the adult group with the same class status, which may indicate that well-educated child immigrants are more likely to take part in mainstream culture. The assimilation function, which could reduce fertility, plays a central role in the fertility behavior of the child group.

\section{Conclusion}

Culture is considered a principal element in man's material and spiritual life. Norms, a medium between a value system and man's conduct, incorporate socioeconomic changes with traditional values. Values hardly alter while norms change periodically. This study explores the effects of reproductive norms and other social-economic-demographic factors on Chinese fertility behavior in Canada. Ethnic fertility patterns are utilized as a normative indicator.

As compared to the British pattern, Chinese reproductive norms as a whole are still characteristically pronatalist. The OLS models in this study have shown that in all three Chinese groups, the Chinese pattern remains more highly correlated with the dependent variable than the British one, demonstrating that Chinese high fertility reproductive norms dominate Chinese fertility behavior in Canada.

Chinese cultural influence diminishes with the increasing exposure to the destination society, as predicted by the assimilation hypothesis. Chinese immigrants experience more origin-specific cultural influence than the Canadian-born group. Child immigrants are more likely to distance themselves 
from the original culture than adult immigrants. It is cultural influence that helps Chinese immigrants quickly attain their original fertility pattern once they are over the initial immigration period. This influence effectively offsets the negative impact of economic insecurities, encouraging immigrants to bear more children.

Multilevel cross-classified model was applied to the examination of compound effects of various factors including economic security, reproductive norms, and immigration process. Chinese cultural influence varies with the extent of husbands' RES and assimilation level. The influence is quite strong when the Chinese families belong to a social class where the husbands have relative economic security or if they move to Canada relatively recently.

Positive effects of RES on Chinese fertility behavior were observed in the multilevel model. Generally speaking, the improvement made in husbands' relative economic security gives their wives more resources to bear children. This effect varies among different groups. The Canadian-born Chinese are highly sensitive to their relative economic status. Changes in RES significantly affect their fertility decision making. However, the positive effect of RES does not work efficiently on immigrants, especially adult immigrants. This, therefore, generates decreasing variances between immigrants and the Canadian-born at the high RES level, and an increasing positive fertility gap at the low RES level. This could be partly attributed to the fact that RES scores are not so closely related to discrimination and economic security for adult immigrants as for the Canadianborn Chinese. Yet, more importantly, factors such as disruption and Chinese reproductive norms play a crucial role in affecting immigrants' fertility behavior.

Assimilation function, combined with "insecurities" effects, explains the lowest fertility level maintained by the Canadian-born Chinese. In any case, however, the power of the assimilation function cannot be exaggerated. Even for the most westernized group, Chinese normative influence is still critical. As shown by Figure 1, without discrimination against minorities, the Canadian-born Chinese would have higher fertility than the majority at all social class levels, due to the influence of the pronatalist culture. With discrimination, however, economic insecurity weakens cultural influence, reducing fertility of the Chinese within the mid-upper classes. Yet, the Chinese within the lower classes would remain highly fertile since discrimination against them is not so severe. 
Cultural Influence, Economic Security, and the

Fertility Behaviour of Chinese in Canada

\section{Figure 1}

Discrimination, Social Status, and Minority Fertility,

\section{Canada: 1991}

Without Discrimination

Discrimination

Fertility

High

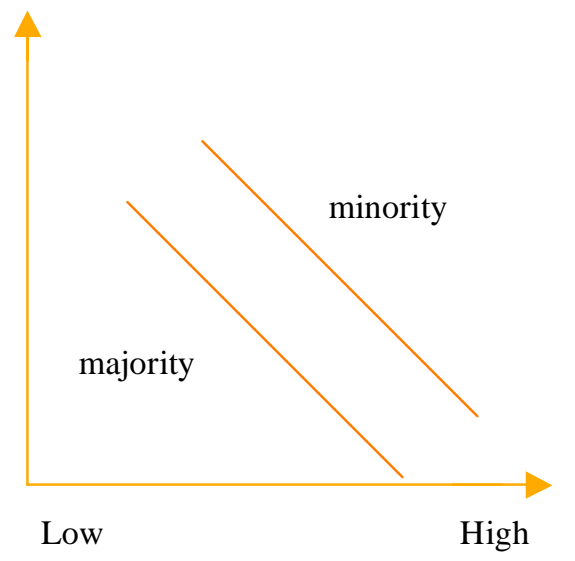

With

Fertility

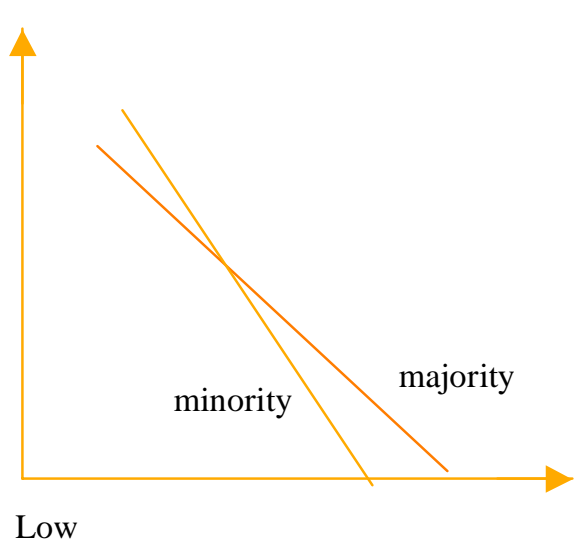

Social Class

Social Class

\section{Endnotes:}

1. One might suggest that gender be employed as an indicator of cultural influence. For the following reasons, however, we cannot adopt such a suggestion. First, PUST does not contain information regarding gender and age of CEB. Second, the sex ratio of an ethnic group is determined by many factors including age 
composition and death pattern, and it would unnecessarily complicate our analysis. Third, if the sex ratio is limited to births, at the aggregate level, this type of ratio hardly bears much cultural effect but mainly functions natural and biological selections unless it is artificially altered.

2. annual income per schooling year $=$ annual income $/$ schooling years

3. Individual RES (in society) = individual wage per schooling year of the minority / community mean of annual wage per schooling year of the majority. Individual RES (in specific class) = individual wage per schooling year of the minority / class mean of annual wage per schooling year of the majority. Class RES = class mean of annual wage per schooling year of the minority / class mean of annual wage per schooling year of the majority. Community RES = community mean of annual wage per schooling year of the minority / community mean of annual wage per schooling year of the majority.

4. Reference period for income/wages reported in the 1991 Canada census is the calendar year 1990 and not 1991. Immigrants who arrived in 1990 would not have a full 12 months to earn income in Canada, and those who arrived in 1991 would have no earnings in Canada, thereby resulting in underestimation of incomes. In the 1991 Canada census, however, year of immigration refers to the year in which landed immigrant status was first obtained in Canada. It is impossible for most immigrants to obtain their landed immigrant status immediately after their arriving. Therefore, income for immigrants, who obtained their landed immigrant status in 1990, would be less likely underestimated. Immigrants, who obtained their landed immigrant status in 1991 and would be most likely underestimated their income, only accounted for $3 \%$ of the total Chinese immigrants. After they are removed from the sample, the average annual wage is $\$ 30240$ for child immigrants and $\$ 27260$ for adult immigrants. Adult immigrants are the lowest income group among the ChineseCanadians.

5. We use CEB for women of all marital status rather than for married women due to the following considerations. First, if CEB were controlled for marriage, the influence of marriage pattern on fertility would be ignored. Ethnic attitude to marriage eventually bears ethnic reproductive norms. Therefore, CEB for women of all marital status would be better than the rate for only married women in describing normative influence. Second, using this type of fertility could avoid into-correlation issues 
such as "ecological fallacy" and "dependency", which very often appear in contextual analysis. In addition, CEB is controlled for ages.

6. In contextual analysis, there are two types of community or group level variables. One type is called "structural," meaning that measurements can be made only from community or group characteristics, not from individuals. The other type of community variable is called "aggregate," meaning that measurements are based on the aggregation of individual characteristics. Both types of community-level factors are sometimes called "contextual" variables (Hong 1979). Both the macro-level variables of RES and CFP used in this study are the "structural" variables. By using the "structural" variables, we could avoid such issues as inter-correlation between two levels variables (or among various levels variables).

7. Use of random coefficient models allows the data analyst to decompose the variance in the dependent variable into the within-context variance and the between context variance, and to study these two sources of variance for the micro-level outcome. Thus, random coefficient multilevel (RC) models are a type of variance components model and will be used in this study. Suppose we have $P$ explanatory variables $X_{p i j}(p=1, \ldots P)$ at the micro-level, and $Q$ explanatory variables $\mathrm{G}_{\mathrm{qj}}(\mathrm{q}=1, \ldots \mathrm{Q})$ at the macrolevel, following the approach of Mason, Wong, and Entwisle (1984), the micro equation is given by

$$
Y_{i j}=\beta_{0 j}+\beta_{p i j}+\xi_{i j}
$$

where $\mathrm{Y}$ is the micro dependent variable, $\mathrm{X}$ is the micro regressor (independent variable), $\mathrm{j}=1, \ldots \mathrm{J}$ denotes contexts and $\mathrm{i}=1, \ldots \mathrm{n}_{\mathrm{j}}$ denotes micro observations within contexts. The intercept $\beta_{0 \mathrm{j}}$ and the slopes $\beta_{\mathrm{pj}}$ are treated as random variables at the macro level that can be modeled by the macro variable $\mathrm{G}_{\mathrm{qj}}$. Then we obtain the macro part of the model:

$$
\begin{aligned}
& \beta_{0 j}=\eta_{00}+\eta_{0 q} G_{q j}+\alpha_{0 j} \\
& \beta_{p j}=\eta_{p 0}+\eta_{p q} G_{q j}+\eta_{p j}
\end{aligned}
$$

where $\mathrm{G}$ is the macro regressor. Equations 2 and 3 represent the effects of contextual characteristics $\mathrm{G}_{\mathrm{qj}}$ on the two parameters of the micro model. We acquire a single equation expression for the multilevel model by substituting Equation 2 and 3 into Equation 1:

$$
Y_{i j}=\eta_{00}+\eta_{0 q} G_{q j}+\eta_{p q} X_{p i j}+\eta_{p q} X_{p i j} G_{q j}+\left(\alpha_{0 j}+X_{p i j} \alpha_{p j}+\xi_{i j}\right)
$$


The basic difference between the random coefficient model shown in Equation 4 and the fixed coefficient model concerns the error structure shown in Equation 2 and 3. The fixed effects models assume these errors are zero. The coefficients of the fixed model can be estimated via OLS.

8. Mln is a multilevel modeling program developed by the Institute of Education, University of London.

\section{References:}

Arnold, F. and Z. Liu. 1986. "Sex preference, fertility, and family planning in China," Population and Development Review 12(2): 221-245.

Arnold, F. and E. C. Y. Kuo. 1984. "The value of daughters and sons: A comparative study of the gender preference of parents," Journal of Comparative Family Studies 15(2): 299-318.

Bean, E.D. and C.H. Wood. 1974 ."Ethnic variations in the relationship between income and fertility," Demography 11: 629-640.

Blau, F. D. 1992. "The fertility of immigrant women: evidence from high fertility source countries," in Immigration and Workforce: Economic Consequences for the United States and source Areas Eds. G. Borjas and R.Freeman. Chicago: University of Chicago Press.

Blau, P. M. and O. D. Duncan. 1967. The American Occupational Structure. New York: John Willey and Sons.

Borjas, G. 1985. "Assimilation, changes in cohort quality, and the earnings of immigrants," Journal of Labor Economics 3: 463-89.

Cheung, P.P.L. 1988. "Marriage market, timing, and policy in Singapore." Paper presented at the Annual Meeting of the Population Association of America, 2123 April, New Orleans.

Cleland, J., J. Verral, and M. Vaessen. 1983. "Preferences for the sex of children and their influence on reproductive behavior," World Fertility Survey Comparative Studies, No. 27. Voorburg, Netherlands: International Statistical Institute. 
Cultural Influence, Economic Security, and the

Fertility Behaviour of Chinese in Canada

Coal, A. J. 1984. Rapid Population Change in China, 1952-82. Committee on Population and Demography. Report No.27. Washington, D.C.: National Academy Press.

Coombs, L. and T. N. Sun. 1981. "Familiar values in a developing society: A decade of change in Taiwan," Social Forces 59 (4): 1229-1255.

Cooney, R. S. and Jiali Li. 1994. "Household registration type and compliance with the `one child' policy in China, 1979-1988," Demography 31(1): 21-31.

Crool, E., D. Davin, and P. Kane. 1985. China's One-Child Family Policy. New York: St. Martain's Press.

Day, L. H. 1968. "Natality and ethnocentrism: Some relationships suggested by an analysis of Catholic-Protestant differentials," Population Studies 22: 27-50.

Fisbie, P.W. and D. Bean. 1978. "Some issues in the demographic study of racial and ethnic population," in Fisbie and Bean, (eds.), The Demography of Racial and Ethnic Groups. New York: Academic.

Ford, K. 1990. "Duration of residence in the United States and the fertility of U.S. immigrants," International Migration Review 24: 34-36.

Freedman, R. 1986. "Policy options after the demographic transition: The case of Taiwan," Population and Development Review 12(1): 77-99.

Freedman, R. and L. C. Coombs. 1974. Cross-Cultural Comparisons: Data on Two Factors in Fertility Behavior. Report of the Subcommittee on Comparative Fertility Analysis of the International Union for the Scientific Study of Population. New York: The Population Council.

Goldscheider, C. and P. H. Uhlenberg. 1969. "Minority-group status and fertility," American Journal of Sociology 74: 361-372.

Goldstein, S. and A. Goldstein. 1983. "Migration and Fertility in Peninsular Malaysia: An Analysis Using Life History Data." Sants Monica: Rand Corporation Report No.N-1860-AID.

Goodkind, D. M. 1995. "The significance of demographic triality: Minority status and zodiacal fertility timing among Chinese Malaysians," Population Studies 49: 45-55. 
Hox, J. J. 1994."Hierarchical regression models for interview and respondent effects," Sociological Methods and Research 22(3) : 300-318.

Huang, J. H. 1982. "Xiandai shenhouzhong xiao de shijian" (Filial Practice in Contemporary Life) in Chuantong wenhua yu xiandai shenhuo yantaohui lunwenji (A Conference on the Traditional Culture and Contemporary Life). Taipei: Committee of Reviving Chinese Traditional Culture. Pp. 285-300.

Jiobu, R. 1988. Ethnicity and Assimilation. New York: State University of New York Press.

Jiobu, R. and H. Marshall. 1977. "Minority status and family size: A comparison of explanations," Population Studies 31: 509-517.

Johnson, Nan E. and Suewen Lean. 1985. "Relative income, race, and fertility," Population Studies 39: 99-112.

Kahn, J. R. 1988. "Immigrant selectivity and fertility adaptation in the United States," Social Forces 6 (1): 108-128.

Kuo, E.C.Y. 1984. "The value of daughters and sons," Journal of Comparative Family Studies 1 (2): 299-318.

Kraft, Ita G. G and Jan de Leeuw. 1994."The gender gap in earnings: A two-way nNested multiple regression analysis with random effects," Sociological Methods and Research 22(3) : 319-341.

Leete. R. 1994. "The continuing flight from marriage and parenthood among the overseas Chinese in East and Southeast Asia: Dimensions and implications," Population and Development Review 20(4): 811-829.

Manson, W. M., G. Y. Wong, and B. Entwisle. 1984. "Contextual analysis through the multilevel linear model,”. Sociological Methodology 6: 72-103.

Rogers, E. M. 1995. Diffusion of Innovations, 4th ed. New York: The Free Press.

Ryder, N. B. 1973. "A critique of the National Fertility Study,". Demography 10: 495-506.

Schemerhorn, R. A. 1970. Comparative Ethnic Relations: A Framework for Theory and Research. New York: Random House. 
Cultural Influence, Economic Security, and the Fertility Behaviour of Chinese in Canada

Scheuch, E. K. 1969. "Social context and individual behavior," in M. Dogan and S. Rokkan, eds., Quantitative Ecological Analysis in the Social Science. Cambridge: MIT Press.

Sly, D. F. 1970. "Minority group status and fertility: An extension of Golscheider and Uhlenberg," American Journal of Sociology 76: 443-459.

Stephen, E. H. and F. D. Bean. 1990. "Assimilation, Disruption and the Fertility of Mexican Origin Women In the United States." Discussion Paper No.3, Population Studies Center, The Urban Institute.

Stephen, E. H. 1992. "Assimilation, disruption and the fertility of MexicanOrigin women in the United States," International Migration Review 26(1): 6787.

Tang, Zongli. 1995. "Confucianism, Chinese culture, and reproductive behavior," Population Environment 16(3): 269-284.

Tang, Zongli, and F. Trovato. 1998. "Discrimination and Chinese fertility in Canada,” Social Biology 45(3-4): 172-193.

Williamson, N. E. 1976. Sons and Daughters. London: Sage Publications.

Willis, R. J. 1973. "Economic Theory of Fertility Behavior," in T.W.Schultz, (ed.), Economics of the Fertility: Marriage, Children and Human. Chicago: University of Chicago Press. Pp. 25-75.

Woodhouse, G., J. Rasbash, H. Goldstein, and Min Yang. 1995. Guide to MLn for New Users. London: Institute of Education, University of London.

Yin, Haiguan. 1988. The Prospects for Chinese Culture. Taipei: The Gui Guan Publishing Company Ltd.

Manuscript Received June 2000; Manuscript Revised August 2000 